\title{
West Nile Virus workshop: scientific considerations for tissue donors
}

\author{
Scott A. Brubaker $\cdot$ P. Robert Rigney
}

Received: 16 November 2011/Accepted: 18 November 2011/Published online: 2 December 2011

(C) The Author(s) 2011. This article is published with open access at Springerlink.com

\begin{abstract}
This report contains selected excerpts, presented as a summary, from a public workshop sponsored by the American Association of Tissue Banks (AATB) held to discuss West Nile Virus (WNV) and scientific considerations for tissue donors. The daylong workshop was held 9 July 2010 at the Ritz-Carlton Hotel at Tyson's Corner in McLean, Virginia, United States (U.S.). The workshop was designed to determine and discuss scientific information that is known, and what is not known, regarding WNV infection and transmission. The goal is to determine how to fill gaps in knowledge of WNV and tissue donation and transplantation by pursuing relevant scientific studies. This information should ultimately support decisions leading to appropriate tissue donor screening and testing considerations. Discussion topics were related to identifying these gaps and determining possible solutions. Workshop participants included subject-matter experts from the U.S. Food and Drug Administration, the Centers for Disease Control and Prevention, U.S. Department of Health and Human Services, Health Canada, the Public Health Agency of Canada, AATB-accredited tissue banks including reproductive tissue banks, accredited eye banks of the Eye Bank Association of America, testing laboratories, and infectious disease and organ
\end{abstract}

S. A. Brubaker $(\bowtie) \cdot$ P. Robert Rigney

American Association of Tissue Banks (AATB), 1320 Old Chain Bridge Road, Suite 450, McLean, VA 22101, USA

e-mail: brubakers@aatb.org transplantation professionals. After all presentations concluded, a panel addressed this question: "What are the scientific considerations for tissue donors and what research could be performed to address those considerations?" The slide presentations from the workshop are available at: http://www.aatb.org/2010-West-NileVirus-Workshop-Presentations.

Keywords West Nile Virus - Tissue donor . Allograft · Research · Risk · Transmission

\section{Opening remarks}

P. Robert Rigney, Jr., Esq.

Chief Executive Officer, AATB

Bob Rigney opened the workshop by welcoming attendees to this "critically important meeting." $\mathrm{He}$ briefly reviewed the history of the Food and Drug Administration's (FDA's) proposed rulemaking on West Nile Virus (WNV) testing and the AATB's response that produced this workshop. He also thanked the various offices within FDA and the Centers for Disease Control and Prevention (CDC) for their assistance in developing the workshop. Mr. Rigney highlighted that the principal goal for the workshop was "to evaluate what is known about $\mathrm{WNV}$, and what studies might need to be done to assess the value of WNV testing of tissue donors. We believe an outcome of this workshop will be to pursue 
scientific studies that adequately characterize WNV, and that will support any final decision made regarding tissue donor testing for WNV."

\section{FDA and regulation of human cells, tissues, and cellular- and tissue-based products}

\section{Melissa Greenwald, MD}

Chief of the Reproductive and Human Tissue Branch, Division of Human Tissues

Office of Cellular, Tissue and Gene Therapies; Center for Biologics Evaluation and Research (CBER), FDA

The FDA works with manufacturers and sponsors who develop tests using post-mortem blood specimens (also known as post-asystole blood specimens). There is a requirement for validation studies for postasystole specimens that are separate from a blood donor screening indication, in part because there has been concern about interfering substances that could prevent the detection of targeted analytes.

"We require additional validation studies in order for the test kit manufacturers to add an indication for use in testing donors whose blood as been collected post-asystole," said Dr. Melissa Greenwald. "So far, all licensed tests that have this donor-screening indication have been validated in tests developed for use in blood donors."

The 2004 guidelines for obtaining the post-asystole indication for use are predicated on obtaining a blood donor screening claim. The data can be submitted for the claim either submitting a biologics license application, or, if one already has a blood donor claim, one can submit a supplement to FDA any time after the test is licensed.

Sensitivity, specificity, and reproducibility studies are required to meet minimal study requirements for a post-asystole specimen claim.

"It is difficult to collect matched pre- and postmortem specimens. So far, everybody that has come to us that has obtained a license to test cadaveric donor specimens has done the unmatched specimen studies," Dr. Greenwald said.

Spiking studies are acceptable for the sensitivity and reproducibility studies-studies where an analyte needs to be present.

Sensitivity and specificity studies require a minimum of 50 specimens; reproducibility studies require
20. Manufacturers or sponsors must use a minimum of three test kit lots per study. They must collect additional information about the donors, such as the time of death and when, how, and where the specimen was collected. The degree of hemolysis should also be documented, along with information about storage and handling.

It was described that in order for the sponsor to provide information in the manufacturer's instructions for use concerning how long you can store the specimen, the types of tubes to use, or shipping and storage requirements, the sponsor must provide data to substantiate these additional instructions.

Laboratory studies demonstrate that a product meets requirements for safety, purity, and potency. Examples include assay precision, lab proficiency, analytical sensitivity and specificity, chemistry, manufacturing, and controls.

Clinical evaluation studies demonstrate the safety and efficacy for a specific intended use. Examples include clinical sensitivity and specificity, reproducibility, and stability.

Analytical specificity measures a test's ability to exclusively identify a target substance rather than different substances. Studies evaluating analytical specificity may look at interfering substances, viral infections, common disease conditions that could yield false positives, and to compare signal strength between pre- and post-asystole to ensure an assay is working.

Clinical sensitivity is a measure of how often a test is positive in diseased donors. It is evaluated by specimens from seroconverting individuals. The frequency of false positive test results are compared for pre- and post-asystole specimens. Theoretically they should have the same amount of analyte in them, but the signals will differ based on how the assays are performing.

"It's the clinical sensitivity that's probably the weakest in the way the tests are currently evaluated, because of the spiking studies" Dr. Greenwald said.

Assay precision measures the closeness of agreement between a series of measurements obtained from multiple sampling of the homogeneous sample under the prescribed conditions.

Reproducibility is a particular measure of assay precision, specifically the precision of measurements obtained when the test is performed in different laboratories. Reproducibility studies include testing 
across multiple operators, lots, and days, at different sites. Twenty specimens are required; each specimen must be tested on six different days, by six different operators, across three different lots.

Dr. Greenwald highlighted the following knowledge limitations:

- When small numbers of specimens are involved, confidence intervals will be large, so specificities estimations are not precise.

- Spiking studies are done to evaluate sensitivity, but for post-asystole specimens the sensitivity studies are really designed to exclude major differences in or problems with the ability of the test to detect a target analyte as compared to blood donor specimens where the test has been well characterized, rather than to stand-alone in characterizing the sensitivity of the assay.

- Sometimes the options, such as the type of specimen tubes, the shipping time, or storage time, are more limited for post-asystole specimens. For example, EDTA (ethylene diamine tetraacetic acid) plasma tubes are typically validated by the sponsor, but other tube types rarely are evaluated.

- Until recently, sponsors have not studied how well a test performs after specimens have been frozen for a few months. Sponsors have been more frequently willing to validate longer storage claims of late.

She briefly described a sensitivity study currently underway comparing the test results from specimens obtained from deceased individuals who have HIV, hepatitis B virus, or hepatitis C virus. She also described a proposed specificity study to compare the specificity of donor screening tests currently licensed for post asystole specimens by comparing pre- and post-asystole specimens obtained from the same individuals and tested across all currently licensed tests. That study protocol is currently in the planning stages.

"We're trying to balance the availability of information about how these specimens perform, and the volume of information, because if we ask for too much, we might get nothing. There's room for improvement on the amount of information we'd like to see, and we're evaluating this as time goes on," Dr. Greenwald said. She noted that many opportunities exist for increased data collection or review to inform donor screening and testing policy.
"That's why we are here today," she said. "We are interested in opportunities to better inform regulatory review. The FDA will always review policy decisions in light of new or better data, once collected."

The tissue safety lab at the CBER is up and running, and ideas for studies are welcome.

\section{Overview of West Nile Virus}

\section{Mike Drebot, PhD \\ Chief, Viral Zoonoses \& Research Coordination: H1N1 Studies \\ Director, Science Technology and Core Services, National Microbiology Laboratory \\ Public Health Agency of Canada}

WNV is a member of the flavivirus genus which consists of more than 70 members of which half are associated with human disease, said Dr. Mike Drebot. The virus is a mosquito-borne virus and a member of the Japanese encephalitis serocomplex. Dr. Robert Lanciotti (CDC) has characterized two main lineages: lineage 2 from Sub-Saharan Africa, and lineage 1 associated with southern Africa, Europe, and North America.

The North American strain of WNV has not changed much, he said; however, there is evidence that the 1999 virus may have evolved to be more efficiently transmitted by mosquitoes.

The 3-'non-translated region of the WNV genome is important for viral replication, however, mutants with 100 nucleotide deletions in this region of the genome have been found. "Dr. Maria Rios identified some of these and we have been working with Maria to try to document their prevalence and whether these are taking up more of a niche," said Dr. Drebot. "In Canada, we have found them not only in field specimens (birds, mosquito isolates), but also in infected blood donors." The Public Health Agency of Canada (PHAC) continues to monitor this, in collaboration with Dr. Rios and others.

Most cases of WNV occur via mosquito inoculation. The virus enters by endocytosis and uncoats. The first round of replication occurs within the skin, where dendritic cells migrate to the lymph nodes. A second round produces viremia and systematic spread to various degrees, with the kidney and spleen being prominent. Rarely, infection of the central nervous system occurs. 
The incubation period is $2-15$ days after exposure, followed by a transient viremia for about 1 week.

"For the most part, you can be viremic and have no antibody response, and you can also be viremic and not show any symptoms," Dr. Drebot said, noting that $80 \%$ or more individuals are asymptomatic. Some are at higher risk due to age, underlying medical conditions, and a host of genetic factors.

Since WNV contains non-structural proteins that interfere with interferon, it can counteract immune responses, as well as interfering with the complement pathway, Dr. Drebot said.

\section{J. Erin Staples, $M D, P h D$}

\section{Medical Epidemiologist, $C D C$} Fort Collins, Colorado

WNV infections in humans are asymptomatic in most or $80 \%$ of persons. However, $20 \%$ of those who are infected will develop a non-specific febrile illness and less than $1 \%$ will develop more severe neuroinvasive disease. Recent blood donor data show that $42 \%$ of individuals infected with WNV will have symptoms. Approximately $25 \%$ will report a rash, weakness, or headache, and close to $15 \%$ will report a fever. Less than $1 \%$ will develop neuroinvasive disease such as encephalitis, meningitis, or acute flaccid paralysis. Overall, approximately $4 \%$ of WNV cases are fatal.

ArboNET is the national arboviral surveillance system in the United States. It is an electronic system developed by the CDC in response to the WNV. It is unique in that it combines human and non-human data. It can readily adapt to new modes of transmission.

Since 2002 the number of dead birds in the United States has gradually declined, while the mosquito population has remained stable at relatively low levels.

The CDC recently published a 10-year summary of WNV activity. During this period approximately 29,000 cases were reported from 1,800 counties in 47 states and the District of Columbia. Maine, Alaska, and Hawaii have had no human cases, while Maine has reported non-human activity.

It is thought that West Nile fever is significantly under-reported. Close to 1.7 million individuals were infected in the United States over the 10-year period, according to serostudies. "If $19 \%$ of those result in fever, then we should have seen over 300,000 cases of West Nile fever, but we've seen less than $5 \%$ of that. Neuroinvasive disease is a better indicator of the epidemiology of the disease," Dr. Staples said.
The disease was established on the east coast for the first 3 years, before expanding across the country. A steady state was reached between 2004 and 2007, followed by declines in 2008 and 2009. It is not possible to predict the incidence from 1 year to the next. The north-central plains states and the LouisianaMississippi region are hot spots.

ArboNET data show human cases of WNV with onset reported between January 2 and December 31, but approximately $90 \%$ are reported between July and September.

\section{Epidemiology in Canada (Mike Drebot, $\mathrm{PhD}$ )}

A total of 4,500 cases of WNV have been documented in Canada, with British Columbia seeing its first case in 2009.

Bird testing in Canada began in 2001. Southern Ontario saw the first bird cases in 2001, and by 2002 nearly 1,000 human cases were reported in Ontario and Quebec. In 2003 the virus swept into western Canada. A drop in 2004 was caused by a cold summer, but the hot summer of 2007 brought high levels of activity. The mid-western provinces of Manitoba, Saskatchewan, and Alberta are hot spots in Canada.

"A recent study found evidence of shedding of the viral RNA in urine 6 years after a group of individuals in Houston showed encephalitis," said Dr. Drebot. "So persistence of the virus is something to keep on the radar."

\section{Discussion}

A participant asked whether the mosquito is initially infected, and whether evidence shows the virus being transmitted from an animal host back into an insect.

Dr. Drebot said that more than 100 species of birds make up the main reservoir for WNV-even crows are viremic and can infect mosquitoes. The virus can persist if it is in the tissues of a dead bird, which are eaten by scavengers.

Responding to a question about whether songbirds carry WNV, Dr. Drebot said birds such as robins have been documented as good amplifying hosts for the virus.

"What's up with British Columbia?" a participant asked, noting that while the vector is there, cases are rare. "We ask this all the time about the states of Washington and Maine," the participant said. Noting 
that the virus needs heat to replicate effectively, Dr. Drebot said, "I think the marine climates are not conducive for good amplification of the virus."

Asked about addressing any pushback from Canada's blood community following years with no cases, Dr. Drebot said, "We continue to test all blood because the logistics and cost benefits are better when testing is uninterrupted. However, this continues to be revisited." A participant commented that Health Canada does not mandate year-round blood testing. "We have two blood systems: the Canadian blood system and Héma-Québec; and Héma-Québec does not do year-round testing."

Dr. Lyle Petersen commented that a study conducted in the 1950s, when WNV was tried as a cancer treatment, showed data on patients who died. At that time, scientists were able to isolate the virus from organs and tissues up to about 40 days after the inoculation. This offers good evidence for persistence in humans. "With respect to longer-term persistence, we did a study in South Dakota looking at seroprevalence for WNV in blood donors, and found that WNV antibody prevalence was about $8 \%$." With so many people infected, if WNV did persist in organs, transmission via that route would be much higher than it is. "My guess is that the long-term persistence issue is probably not that important other than for a short period of a month or two," Dr. Petersen said.

Dr. Drebot agreed, but asked whether Dr. Petersen was talking about the persistence of viable virus. Some evidence indicates that these viruses can integrate. "It could be that what we are picking up is expression of the virus, but not an infectious virus."

A participant asked panelists whether they thought WNV prevalence would settle down, similar to eastern equine encephalitis or Japanese encephalitis; if it does, "Why are we talking about preventing transmission and tissue donors? Do we have to start testing for all the other arboviruses out there?"

Dr. Drebot said that in Canada, the intention is to continue monitoring the virus, since viremia is more pronounced in various amplifying hosts (e.g., birds) for WNV than other arboviruses. Dr. Staples added that it is impossible to predict where the disease will occur each year. "It could be quiet for years and then you see thousands of cases, so do we not want to be screening when that happens? I do not know the answer to that yet."
Asked about the challenges in collecting epidemiological data on the numbers of infected humans each year, Dr. Staples said the CDC and selected state health departments are looking at under-diagnosis and under-reporting.

Another participant asked whether the testes and ovaries harbor the WNV; Dr. Staples said no one has examined this question. The participant asked whether it would be useful to provide Dr. Staples' lab with human tissue samples for assessment; Dr. Staples said this would definitely be a consideration. Dr. Drebot added that this could become part of a study design.

A participant asked the panel when they would feel comfortable in saying the incidence of WNV is declining. Dr. Staples said that due to all the biological factors involved, "I do not think I will ever feel comfortable with it." Another participant agreed: "Five years does not make a trend. These are episodic diseases."

\section{Assessing risk of transmission through tissues: a CDC perspective}

\section{Matt Kuehnert, $M D$}

Director, Office of Blood, Organ and Other Tissue Safety

$C D C$

"Given that there are no reports of tissue-transmitted WNV, we have to look at what we know about blood and organ transmission," said Dr. Matt Kuehnert. "Also, we can look at other viruses to give us perspective on how WNV might behave."

The CDC does risk assessment through investigations, surveillance, statistical modeling, and research. Investigations are prompted by invitations based on word of possible transmissions; this information comes from the FDA, the Health Resources and Services Administration, the United Network for Organ Sharing (which operates the Organ Procurement and Transplantation Network), and an OPTN disease transmission advisory committee that collects cases related to organ transplantation. State health departments, tissue banks, organ procurement organizations (OPOs), clinicians, pathologists, laboratory staff, and even patients and their families can provide important clues about potential cases. 
Tissue allografts have a risk of disease transmission. Processing can mitigate risk; however, techniques are not well standardized from tissue bank to tissue bank and overall efficacy is not well defined. For example, in one 1985 case, HIV was transmitted by unprocessed frozen tendon and femoral heads, but not transmitted by freeze-dried or irradiated products. In another case, hepatitis $\mathrm{C}$ was transmitted to multiple organ and tissue recipients, but only by tendon and saphenous vein.

"This case is important because it ties in the relationship between organ and tissue," said Dr. Kuehnert. "Unfortunately, it was a lesson in retrospect where the organ recipients were recognized as having HCV infection but the tissue bank was unaware and ended up releasing the infected tissue." This reinforces the importance of communication between OPOs and tissue banks as well as of understanding risk.

Dr. Kuehnert addressed the importance of organ donors that have transmitted WNV despite having evidence of IgM and lacking evidence of viremia and whether this reflects a persistent reservoir outside the blood in some patients. A case in Louisiana involved an organ transplant recipient who was infected, and the organ donor had been transfused. The IgM and nucleic acid testing (NAT) from serum/plasma were both negative. The blood donation was implicated for WNV, suggesting the organ donor as a conduit for infection despite the lack of evidence by NAT. "Presumably there was a hemodilution effect to explain those findings, but we can only propose that as a hypothesis," said Dr. Kuehnert.

The question of how viral loads and blood donors are meaningful in terms of tissue type, and in terms of processed tissue, is an important one. "We really have to take them [each tissue type] case by case."

If the latency period for WNV is longer than expected, it can affect adequate surveillance.

While reporting systems are in place for organ and tissue safety, FDA HCT/P regulations extend only to the hospital door, Dr. Kuehnert said. Tissue banks can only report an adverse reaction if they know it occurred, but if the clinicians do not report it, this leaves a gap.

There are real issues with tissue surveillance. Barriers to surveillance include lack of fundamental solutions for traceability. First, tissue nomenclature is not standardized.
Also donor identifiers are fragmented across the system, so having a unique identifier would help clinicians to link events. "A [surveillance] platform hasn't been developed, but AATB has been very involved in trying to create the infrastructure to facilitate this," Dr. Kuehnert said. Denominator data would be one benefit of having a working tissue surveillance system. Research could feed into surveillance.

The risk for transmission is unknown in most tissues. Tissue characteristics should be taken into context. For example, in a recent case of chronic Q fever there was a question of the risk in blood and tissues. While it was thought that the risk was small for blood and most tissues, someone brought up bone marrow transplantation.

"When you think about [the potential transmission risk of] heart valves and bone marrow, it is a different story", Dr. Kuehnert said.

Much can be learned from the organ world with respect to disease transmission, because the rates are so much higher compared with blood and tissue.

"After solid organs, I think we need to look at minimally processed tissue in terms of the highest risk. I think there would be minimized risk as tissue is more heavily processed, but that needs to be shown."

Scaled risk assessment is the goal, given the minimized risk in heavily processed tissue, and the small number of minimally processed tissue that may have greater risk: "We would like to be involved with projects that focus on where we need to focus our surveillance, and include certain groups of clinicians that use those tissues at highest risk," Dr. Kuehnert said. "I am not sure that statistically you might expect a WNV transmission in tissue. We haven't done that statistical modeling yet, but I think it could be useful."

\section{Recipient demographics and risk considerations}

\section{Marian G. Michaels, MD, MPH \\ Professor of Pediatrics and Surgery, Division of Infectious Diseases \\ Children's Hospital of Pittsburgh}

Clinical reporting is passive and relies on health care workers thinking about the disease, being able to diagnose it correctly, and reporting it consistently, said Dr. Marian G. Michaels. 
ArboNET data show that risk for neuroinvasive disease increases with age, although a study from North Dakota showed the younger population to be at highest risk for acquiring the disease. Immunosuppressed individuals are also at high risk for symptomatic disease.

"If the decision is made not to have universal screening, there will need to be good communication with the blood banks," Dr. Michaels said. "Since there is no specific treatment the emphasis has to be aimed at prevention."

Supportive care is the mainstay of treatment. Immunoglobulin has been of interest as a potential treatment due to the suggestion that prior immunity should offer protection and anecdotal reports of the use of high titer WNV specific IVIG seemed to offer benefit. However, a randomized controlled trial of a single dose of the high-titered WNV IVIG $(0.5 \mathrm{mg} / \mathrm{kg})$, versus standard IVIG or placebo, failed to provide clinical benefit in adults with symptomatic disease. Further studies of different dosing schedules, or its use for recipients of organs from a donor found to have $\mathrm{WNV}$, need to be investigated further.

Animal studies have shown that interferon alpha- $2 b$ may improve survival, particularly with increasing doses. Likewise, case reports suggest temporal improvement. Looking at a non-controlled, single-center study of the St. Louis flavivirus (another Arbovirus), 15 subjects received interferon and 17 did not; only two of the 15 treated subjects had serious disease requiring hospitalization of more than 1 week whereas 11 of the 17 untreated subjects had serious disease requiring hospitalization of more than 1 week.

Hamster studies have shown that a humanized monoclonal antibody currently in clinical trials has potential, even after neurological symptoms have developed.

Studies show that ribavirin is associated with worse outcome and is therefore contraindicated.

\section{Discussion}

Noting, "We are good at coming up with national policies, but not localized policies," a participant asked how to address issues that might be more localized. For example, while it might not be appropriate to test a donor in Maine, testing might be indicated in Colorado. "How do we become flexible in our policies, and does the FDA have mechanisms to address these issues?"

Dr. Greenwald acknowledged that in terms of policy, this is indeed challenging. Given that it is impossible to predict where the concern will be at any given time, "I do not have the answer as to how this challenge can be addressed."

Another participant commented that Alaska is visited all summer by thousands of tourists and big ships from around the world. This illustrates the difficulty of determining where an individual has spent time before they are presented as a potential donor.

Noting that better communication is essential, Dr. Greenwald said, "I think this is why it made sense to go with universal testing from the blood bank side."

A participant commented that as an association, those present should try to develop communication between blood establishments, collection centers, OPOs, and tissue banks. However, the participant said it would be important to consider how this would fit into the regulatory scheme and testing.

\section{Experiences using WNV NAT}

\section{Jerry Niedzinski, BS, CHS \\ Senior Scientist \\ LABS, Inc.}

Jerry Niedzinski compared the Procleix ${ }^{\circledR}$ WNV test (Novartis Diagnostics) that is based on transcriptionmediated amplification (TMA), with the Cobas TaqScreen MPX test (Roche Molecular Diagnostics Products) that uses real-time polymerase chain reaction (PCR).

Novartis claims a sensitivity of 100 copies for tissue and live donor tissue samples. Roche claims a sensitivity of 117-365 copies, depending on the level of hemolysis of the sample. LABS, Inc. tested the sensitivity of both assays and found them to be adequate.

Both assays require a spiking of the sample with a positive internal control. If the positive internal control fails, there is a potential inhibitor. The Novartis and Roche assays respond differently to inhibitors.

"It is possible that the internal control may not work for West Nile assays," Mr. Niedzinski said. He 
gave an example where the internal control did not detect an inhibitor for both the TMA and PCR assays.

The WNV NAT screening assays do not have a repeat or discriminatory test for reactive samples. Therefore, these initial reactive, non-repeatable results must be reported as reactive.

The Novartis and Roche assays are complex and should be performed by experienced lab technologists.

Asked how many deceased tissue donors his lab tests each year for WNV, Mr. Niedzinski said they have done about 3,000 as of July 2010.

\section{Karen Norman}

Executive Director of Quality Assurance

RTI Biologics, Inc.

Karen Norman said her experience with WNV NAT testing has been consistent with LABS, Inc.

RTI Biologics uses a semi-automated format for small volume runs of $9-12$ donors each. The kit is based on an average of 55 tests per run, but the lab has worked out an arrangement with the manufacturer whereby it is billed only for the portions that are used. WNV is temperature-sensitive, so the laboratory temperature is well controlled, with back-up generators. A unidirectional workflow is in place to control contamination. Invalid runs and specimens require repeats, and $1.5 \mathrm{~mL}$ samples are recommended.

There is a short window to get the test done: generally $24 \mathrm{~h}$ at $2^{\circ}-15^{\circ} \mathrm{C}$. If one centrifuges and refrigerates the specimen, an additional 7 days can be added for plasma. Two additional days can be added for serum. If stored at $-70^{\circ} \mathrm{C}, 11$ additional days are allowed for both plasma and serum samples.

An individual specimen can be reactive, nonreactive, or invalid. No further testing is done on non-reactive specimens. Invalid specimens can be due to inhibitory substances and these can be diluted and re-run.

"An invalid run is usually due to the calibrators not meeting the acceptance criteria, and all specimens on that run must be repeated," Ms. Norman said.

RTI Biologics was part of the study to get the WNV NAT kit on the market. It analyzed 4,569 samples, 16 of which gave a positive result. All 16 were negative, or non-reactive, when re-tested by an independent lab. Fifteen were non-reactive for IgM and IgG.

Testing continued after the end of the study in December 2005. The invalid run rate in 2008 was 3\%; in 2009 it was $7.5 \%$. An investigation found that the
2009 increase was tied to an individual technologist who was subsequently retrained. The invalid specimen rate for an individual test was $0.4 \%$ in 2008 and $1 \%$ in 2009. The reactive rate was $0.35 \%$ in 2008 and $0.39 \%$ in 2009, which was consistent with LABS, Inc.

Maria Rios, PhD

Research Biologist

OBRR/CBER/FDA

Following Dr. Lyle Petersen's 2002 report on the risk of transmission of WNV by transfusion, a cooperative effort between screening assay manufacturers, blood collection facilities and the FDA led to the implementation of screening of all U.S. volunteer blood donations using mini-pool nucleic acid testing (MPNAT) under FDA approved INDs by July 2003. In November 2003, recognition that transmissions of WNV by blood transfusion had occurred led to retrospective studies that found that MP-NAT detected only $75 \%$ of the infected donations, said Dr. Maria Rios. "The blood community re-evaluated the screening criteria and implemented individual donor NAT (ID-NAT) during epidemic periods," Dr. Rios said.

Screening of blood donors by MP-NAT and implementation of ID-NAT during epidemic periods from 2003 to 2009 prevented 3,000-9,000 potential transmissions of WNV by transfusion. However, despite selective implementation of ID-NAT, there have been 11 recognized transmissions by transfusion during those 7 years.

These occasional transmissions of WNV may be related to the fact that infection often produces lowlevel viremia leading to inconsistent test results. Viral detection is challenging, as evidenced by the need to implement an ID-NAT during certain periods to replace MP-NAT in blood donors. In addition, the positive predictive value of the tests varies with the incidence.

The FDA is interested in getting data to demonstrate test performance post licensure.

\section{Testing human and non-human animal tissue}

Robert Lanciotti, PhD

Chief, Diagnostic \& Reference Library, Arbovirus

Disease Branch,

CDC, Fort Collins, Colorado 
The CDC looks for WNV in sentinel chicken flocks, mosquito populations, and dead bird populations, said Dr. Robert Lanciotti. It looks for the viral RNA in collected mosquitoes or for the virus in amplifying hosts; NAT is the test of choice.

Most tissue specimens received by the $\mathrm{CDC}$ are as a result of neuroinvasive disease and serological testing is the most valuable tool, Dr. Lanciotti said, noting that combining with NAT helps to confirm infection.

Human infection is confirmed by the presence of IgM in serum or cerebral spinal fluid (CSF). Seroconversion is another indicator. To enhance diagnosis, one can look for virus or viral RNA in serum CSF.

The CDC uses an IgM-ELISA test on beads, which allows for multiplexing. A plaque reduction neutralization test confirms specificity of infection.

"The advantage of the microsphere assay is that we can have unique bead sets-West Nile, St. Louis or Eastern encephalitis - creating geographic panels, and then take a single serum specimen and test it to all," Dr. Lanciotti said.

Confounding the serological diagnosis is cross reactivity among the flaviviruses. Japanese encephalitis can cause an indistinguishable reaction to $\mathrm{WNV}$ and confirmation is required in a follow-up neutralization test.

NAT tests are the most sensitive for detection of WNV, followed by isolation of virus and detection of antigen. The GenProbe and Roche tests have been FDA-cleared for screening donor plasma.

Approximately 100 organs collected in autopsies have been tested. Brain tissues are generally positive for viral RNA. Real-time PCR can detect it nearly $100 \%$ of the time. West Nile RNA has not been detected in organs collected from autopsies or from urine specimens.

\section{Discussion}

A participant commented that a fair bit of serum plasma - up to half a milliliter-is needed to ensure that PCR is accurate. Dr. Lanciotti agreed that this is probably the most important part of increasing sensitivity in the NAT assay.

Another participant asked whether urine samples were collected from living patients with neurologic disease or from cadavers; Dr. Lanciotti said both sources were used.
Asked whether particles can precipitate, Dr. Lanciotti said they have not looked at that, but that they routinely use a vortex mixer.

Regarding the autopsy samples, a participant asked whether the negative organs were from patients who had died from West Nile disease, or who had died from another cause. Dr. Lanciotti said they were confirmed West Nile cases; however, "We do not see the cause of death report." He said the next few speakers would address the relevance of this information to current issues in the tissue bank industry.

\section{Tissue handling and processing studies}

\section{Carrie Hartill}

Chief Scientific Officer and Vice President, Quality Assurance \& Regulatory Affairs

RTI Biologics, Inc.

For more than a decade, groups from around the world have been identifying relevant and modeled viruses to determine how tissue processing and handling practices may help to minimize and mitigate existing viruses, said Carrie Hartill. As well, they have been characterizing and allocating different types of pathogens, with the aim of creating better risk assessment.

WNV is a relatively low-resistant envelope virus, and fragile to handle. Model viruses are chosen because they tend to be hardier. Viruses are relatively easy to kill and/or remove. As pathogen inactivation technologies are developed, they are categorized according to fragility.

"In the big scheme of things, while we do need to focus on viruses, they are not our biggest problem in the tissue banking world," Ms. Hartill said.

No single approach addresses all problems. Cold storage and freezing can serve to inactivate some organisms, but they are also preservation techniques for others. Removal of blood and lipids is critical when dealing with blood-borne pathogens. Storage at room temperature for more than 30 days inhibits many pathogens. Studies comparing traditional and new processing and sterilization techniques are lacking.

"Without having any visibility to all of these things, the regulators are trying to develop policy about what happens when the next pathogen comes along," Ms. Hartill said. "The industry has the responsibility to give them the data." 
The World Health Organization (WHO) has taken the approach of looking at transmission risk by cell and tissue type. Infectivity studies are needed, Ms. Hartill said, noting that the assays are in place.

When developing a pathogen inactivation study, fluid exchange and dynamics are critical parts of evaluating the mechanical aspects. As well, tissue must not be harmed during techniques used in processing, such as irradiation. There are few published studies describing these processes.

Alyce Linthurst-Jones, PhD, RAC

Project Manager

LifeNet Health

Since the introduction of its Allowash $\mathrm{XG}^{\circledR}$ cleaning process in 1995, LifeNet has delivered more than two million tissue grafts with no incidents of disease transmission, said Dr. Alyce Linthurst-Jones. The process begins with centrifugation to remove the blood and bone marrow. Next, warmed hydrogen peroxide is added to kill bacteria. Ultrasonication at elevated temperatures with Allowash ${ }^{\circledR}$ detergent solution helps solubilize the bone marrow and removes infectious agents. Finally, ultrasonication with hydrogen peroxide cleans and removes agents.

"We validated this process in the early 2000s, ensuring that weight of bone to volume of reagents used is consistent to support the validation that was performed," Dr. Linthurst-Jones said. "We terminally irradiate, and part of making sure that our dose is valid is making sure we have a consistently low bio-burden going into the gamma radiation step. The disinfection portion of Allowash is essential to maintaining the validity of our radiation dose."

In the viral inactivation studies performed with Allowash XG, more than three logs were killed for all the model viruses. For WNV specifically, $10.4 \operatorname{logs}$ were achieved.

"We were able to substantially clear and/or inactivate enveloped, non-enveloped DNA, RNA, and double-stranded genomes," Dr. Linthurst-Jones said.

Mary Malarkey

Director

$O C B Q / C B E R / F D A$

Mary Malarkey listed the following gaps and challenges in tissue processing, as seen from a regulator's perspective:
- Available data are lacking.

- Little active research is being conducted in academia.

- Evaluation of irradiation processes for viruses of interest is lacking.

- Validation and viral clearance studies are reviewed on inspection rather than in the application process.

- There has been lack of consideration of preprocessing and/or sterility results for bacterial and fungal agents (not related to viruses).

- There have been gaps in validation where particular steps have not been looked at. Lack of validated processes or microbiological methods has led to transmission.

- Changes in a process where validation has not been done have led to transmission.

"Even in the best possible world there is human error, and this is always a concern," Ms. Malarkey said.

\section{Discussion}

Asked about dose parameters for irradiation, Scott Brubaker offered that relevancy is "aimed at the validation of your process and not to set a minimum dose." An AATB task force is developing a guidance document to set minimum expectations for validation processes, including culture methodologies, and using examples for different tissues. "We have realized this gap and we are on track to finish it," he said.

Ms. Hartill added that the irradiation standards were not promulgated with the idea of affecting biological material. They were focused on traditional bacterial reduction. Some organisms are highly susceptible to radiation, while others are highly resistant and more susceptible to chemical treatment.

\section{Roundtable discussion: scientific considerations for tissue donors}

"What are the scientific considerations for tissue donors and what research could be performed to address those considerations?"

During a panel discussion of the scientific considerations for tissue donors, and research that could be 
performed to address those considerations, Dr. Francisca Agbanyo noted that Health Canada recommends WNV testing for all tissue donors, but it is not mandatory.

Dr. Harvey J. Stern said no evidence shows that WNV is a sexually transmitted disease. "Even if nucleic acids are present in reproductive tissues, is it capable of being present in sperm and, if present, would it survive processing?" He suggested that animal experimentation could help discover the answers to these questions.

A participant said, "We struggled with this issue with living donors for organ transplantation," and asked whether the safest process would be to test those individuals and defer them for a period of time, since it is theoretically possible to procure the specimens 2 or 3 months after the PCR had been detected. This would mean applying the principle of "first, do no harm" to using tissue from a living person.

Dr. Stern said this might be possible, but would not take into consideration the expense of testing. "I do not think there is a problem testing in circumstances where there is a real risk of transmission," he said. "It would be nice to know if this is an issue. I think the jury is still out.

Dr. Bruce Bodner said that from the eye-banking perspective, the FDA's ongoing initiative regarding evidence-based regulation is very important and certainly welcome. While some believe the cornea to be a privileged organ, he said, it is not known whether it has any viral load, and if it does, whether it can transmit the disease.

Dr. Celia Witten agreed that biovigilance is critically important to protect the public. The FDA does not always want to wait until transmission is proven before instituting a protective measure. It would be useful to have studies on donor populations for WNV and other diseases; it would also be helpful to have published information on processing in a way that would enable people to draw general conclusions over time.

Dr. Lyle Petersen emphasized the importance of estimating the risk in tissue donors. "We can begin to create models to estimate the risk and the benefits of screening, and I would advocate for doing that," he said. "I also think we need good surveillance."

Dr. Greg Ray said continued research is needed to look at processing methods directed at viral clearance. As well, he said, "I am not sure the data indicate that WNV is a serious concern for the tissue donation population. There needs to be a well-defined risk analysis model."

Dr. Michael Ison said it is now recognized that the incidence of disease transmission is between 0.2 and $1 \%$ of all organ transplants. Many feel that there has been no significant disease transmission (in tissue transplantation) resulting in neuroinvasive disease, "but unless you show me some PCR data in those patients (tissue recipients) who have fevers, I do not believe that we can definitely say there has not been any transmission (from tissue allografts)." He agreed that intensive donor screening and (tissue) recipient follow-up over a long period of time would be useful.

These issues apply to all emerging infections, said Dr. David Gocke. He asked about the threshold of evidence that must be accumulated "before we embark on an elaborate, expensive, new test development for WNV or any other disease."

We need to mobilize leadership in science and prevention to effectively use our healthcare dollars," said Dr. Jerry Holmberg. In reference to biovigilance he noted that our beliefs dictate our behavior. For example, "if you believe that there is no need for surveillance and are not willing to put in place mechanisms to look for problems, you are probably going to continue in that frame of thinking and miss opportunities for process improvement." More surveillance and data collection are needed, to determine whether there is a problem, as well as how to approach it.

Dr. Holmberg said the tissue community must step up its public information efforts, which will in turn spur research. Noting that there is "a void in respect to tissue research support," he asked participants to consider how to stimulate manufacturing to respond to this orphan community. Microarray technology, based on genomic sequences, was referenced as an example of new technology, which has potential for the tissue and organ communities. He noted that health care reform provided resources, especially for disease prevention; the tissue community should go out and seek opportunities for advancement. A participant remarked, "We are good at coming up with national policies, but there are more diseases that may affect only small locales. We need to be flexible in our thinking." Another noted that an inexpensive way to address protection would be to have regional blood banks send emails to OPOs and eye banks to keep everyone informed of current trends. 
A participant recommended collaborating with local and state health departments to learn of endemic diseases unique to specific locales, while another said, "We draw donors from all over the country. There is no limitation on the amount of testing we would need to do. It could not be done on a regional basis."

A participant challenged this, saying that if there is a unique situation, triggered by unique history, "you can consider what additional testing needs to happen." Noting that many donors are already deferred because of malaria, a participant said that in the blood bank world, this is a larger issue. "I wish there were such a thing as medical director discretion, but the exclusionary rules are very broad."

\section{Closing remarks}

Scott A. Brubaker, CTBS

Chief Policy Officer

AATB

Much work remains to be done, said Scott Brubaker. He described that the AATB would start working with the FDA and CDC to develop study protocols to obtain data that will characterize the virus as it relates to donated conventional and reproductive tissues; he noted that this is already being done with $\mathrm{T}$. cruzi, with much help from the CDC and input from FDA. We have ongoing studies to find out if normal tissue handling has a negative effect on that parasite. Related studies should occur with WNV. He thanked participants for attending, and closed the meeting.

\section{Participants}

Moderator: Scott A. Brubaker, CTBS, Chief Policy Officer, AATB

Opening Remarks: P. Robert Rigney, Jr., Esq., Chief Executive Officer, AATB

Speakers (in order of appearance):

- Melissa Greenwald, MD, Chief of the Reproductive and Human Tissue Branch, Division of Human Tissues, OCTGT/CBER/FDA

- Mike Drebot, PhD, Chief, Viral Zoonoses \& Research Coordination: H1N1 Studies; Director, Science Technology and Core Services, National Microbiology Laboratory, PHAC
- J. Erin Staples, MD, PhD, Medical Epidemiologist, CDC at Fort Collins, Colorado

- Matthew Kuehnert, MD, Director, Office of Blood, Organ and Other Tissue Safety, CDC

- Marian G. Michaels, MD, MPH, Professor of Pediatrics and Surgery, Children's Hospital of Pittsburgh, Division of Infectious Diseases

- Jerry Niedzinski, BS, CHS, Senior Scientist, LABS, Inc.

- Karen Norman, Executive Director of Quality Assurance, RTI Biologics, Inc.

- Maria Rios, PhD, Research Biologist, OBRR/ CBER/FDA

- Robert Lanciotti, PhD, Chief, Diagnostic \& Reference Library, Arbovirus Disease Branch, CDC, Fort Collins, Colorado

- Carrie Hartill, Chief Scientific Officer and Vice President, Quality Assurance \& Regulatory Affairs, RTI Biologics, Inc.

- Alyce Linthurst-Jones, PhD, RAC, Project Manager, LifeNet Health

- Mary Malarkey, Director, OCBQ/CBER/FDA

\section{Roundtable Invitees}

- Celia Witten, PhD, MD, Director, Director, Office of Cellular, Tissue, and Gene Therapy, CBER/ FDA

- Francisca Agbanyo, PhD, Chief, Blood, Cells, Tissues, Organs and Xenografts Division Centre for Blood \& Tissue Evaluation Biologics and Genetic Therapies Directorate, Health Products and Food Branch, Health Canada

- Bruce Bodner, MD, Medical Director, Lions Medical Eye Bank

- David Gocke, MD, Medical Director, Musculoskeletal Transplant Foundation

- Greg Ray, MD, FCAP, Medical Director, CryoLife, Inc.

- Harvey J. Stern, MD, PhD, Medical Director, Fairfax Cryobank, Genetics \& IVF Institute

- Jerry Holmberg, PhD, MT (ASCP) SBB, Senior Advisor to the Secretary of Health and Human Services (HHS) for the Advisory Committee on Blood Safety \& Availability

- Lyle Petersen, MD, MPH, Director, Division of Vector-Borne Diseases, CDC

- Michael G. Ison, MD, MS, Past Chair, OPTN/ UNOS Disease Transmission Advisory Committee; Associate Professor, Divisions of Infectious 
Diseases \& Organ Transplantation, Northwestern University Feinberg School of Medicine

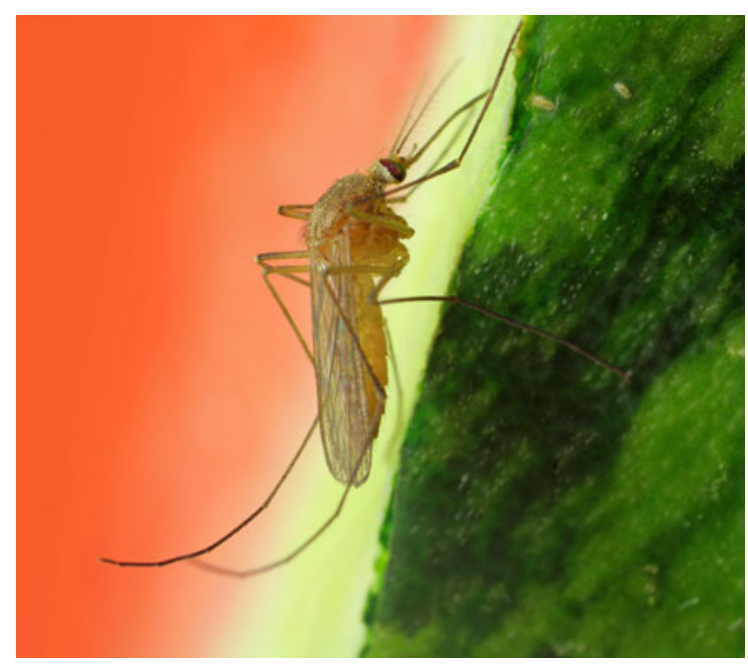

A Culex pipiens mosquito on a watermelon. This is a primary vector of WNV in North America that bites both birds and humans (anthropophagy)

Open Access This article is distributed under the terms of the Creative Commons Attribution Noncommercial License which permits any noncommercial use, distribution, and reproduction in any medium, provided the original author(s) and source are credited. 